\title{
UNINTELLIGIBLE SPEECH: \\ LISTENERS' AWARENESS TO INDONESIAN-ACCENTED SPEECH WITH PRONUNCIATION ERRORS
}

\author{
Syifa' Khuriyatuz Zahro \\ Universitas Islam Darul 'Ulum, Lamongan, Indonesia \\ E-mail: syifazahro@unisda.ac.id
}

Received: 2021-05-09

Accepted: 2021-06-19

\begin{abstract}
There have been widely exposed researches that analyze accented and intelligible speech of foreign language; yet, the study concerning listeners' awareness of the pronunciation errors is hardly found. Therefore, the current study aims to find out segmental features and the source of errors that have caused unintelligible speech of Indonesian-accented speech and describe the listeners' awareness of the errors. This descriptive qualitative research investigates listeners' transcripts of Indonesian-accented speeches through purposive sampling. The standard orthography transcripts are then transformed into phonemic transcripts. They are analyzed by error analysis based on phonological operation by Davenport and Hannahs. The result is further checked by the listeners to generate their awareness of the errors through interviews. There are consonants causing unintelligibility more than vowels. Furthermore, it is found that there are six pronunciation features affecting listeners' awareness of speakers' pronunciation errors: 1) aspiration, 2) spelling system, 3) blended phonemes, 4) absent phonemes, 5) different articulation, and 6) homophone in the research.
\end{abstract}

Keywords: Accent; Intelligibility; Listeners' Awareness; Pronunciation Errors

\section{Introduction}

The difference between speakers' native language and some foreign languages brings about non-native speakers' difficulty in recognizing acceptable foreign language sounds. Such a problem affects non-native speakers' production of various peculiar foreign language sounds compared to their native language sounds. As a result, the speakers may produce unintelligible speech and fail to speak intelligibly.

Intelligibility, the foremost fundamentals in non-native speaking production, is defined as the degree by which listeners' accurate understanding in association with foreignlanguage speakers utterances is matched (Crowther, 2020). The equality between the listeners and speakers in understanding the words requires speakers to make their pronunciation intelligible. Additionally, Smith and Nelson (2019) declares that two notable factors affecting intelligibility are speakers' language proficiency and speakers' and listeners' familiarity with English variety.

One language variety that numerous researchers concern about intelligibility primarily seek is an accent. A native-accented speaker can speak a foreign language also in an accented way called a foreign accent. Studies concerning the intelligibility of foreign- 
Unintelligible Speech: Listeners' Awareness to Indonesian-Accented Speech with Pronunciation Errors, Syifa' Khuriyatuz Zahro

accented speech have proven that an accented, and intelligible speech is independent (Munro \& Derwing, 2020; Zahro, 2019). Thus, a strong accented speech to speak a foreign language can be intelligible (Crowther, 2020; Zahro, 2019). In other words, foreign-accented speech is considered not pathological speech (Munro \& Derwing, 2020). Furthermore, the observed factors to affect intelligibility are pronunciation inaccuracy (Yule, 2020; Zahro, 2019) and pronunciation clarity of foreign sounds produced by the accented speakers (Behrman et al., 2020; Zahro, 2019).

Copious studies on pronunciation in relation to intelligibility and foreign accent have been sought, and the utmost of them focus on the pronunciation purely (Rahimi \& Ruzrokh, 2016; Suntornsawet, 2019) and also on the perception of accented speech (Behrman et al., 2020; Sereno et al., 2016). Furthermore, several pieces of research about perception on pronunciation errors have been found related to accented speech on the level of segmental (Gao \& Weinberger, 2018; Lindemann, 2017; Liu \& Jaeger, 2019). Segmental errors of both consonants and vowels are the primary origin of the listeners' trouble to measure the speech's intelligibility (Levis, 2018). Additionally, Crowther (2020) notes that segmental sound is one of the significant measures of speech production. Therefore, the need to focus on errors at the segmental level is undeniably crucial in examining both accented speech and its' intelligibility.

Another study examining speakers' awareness of their comprehensibility yields that speakers' awareness through a self-assessment of their speaking has affected their comprehensibility (Strachan et al., 2019). Nonetheless, a question raises whether listeners are aware of speakers' pronunciation errors that can contribute to their intelligibility. Many preceding studies have investigated foreign accent, intelligibility, and pronunciation errors but hardly found studies related to listeners' awareness of the pronunciation errors.

Given the above considerations, the research aims to find out segmental features and the source of errors that have caused unintelligible speech of Indonesian-accented speech and describe the listeners' awareness of the errors. Therefore, the present paper attempts to examine pronunciation features that caused unintelligible speech of Indonesian-accented speech concerning the listeners' awareness of the speakers' errors.

\section{Literature Review}

\subsection{Intelligibility}

The ultimate significant aim of non-native speakers' speaking production is Intelligibility (Levis, 2018: 15). Crowther (2020) and Munro and Derwing (2020) agree to define intelligibility as the amount by which listeners' accurate understanding matched words by words uttered by speakers. The definition denotes that intelligibility only emphasizes the listeners' recognition of words, phrases, or sentences spoken by the speakers. To this effect, intelligibility can be reached by having the listeners do a transcription or dictation task where they have to write out words by words (Levis, 2018). In other words, unintelligible speech is the one that is not precisely written words by words by the listeners (Levis, 2018). Therefore, equality between the listeners' understanding and speech is required to be an intelligible speaker.

\subsection{Accent}

Foreign-accented speech is not pathological speech, but it is unusual sound, different from native speakers' standard (Munro \& Derwing, 2020). A foreign accent, an accent used to speak a foreign language, is assumed as part of intelligibility's measurement (Levis, 2018). 
Some foreign-accented speeches are strong, whereas the others are less. A strong foreignaccented speech is supposed to have potential interference of one's intelligible speech (Levis, 2018). Nonetheless, intelligibility to foreign accents has been broadly sought and yielded for their independence (Munro \& Derwing, 2020; Zahro, 2019). This means a strong foreign-accented speech can be intelligible (Crowther, 2020; Zahro, 2019) as long as the pronunciation is clear and accurate.

\subsection{Pronunciation Errors}

One prevalent factor contributing to intelligibility measurement is pronunciation inaccuracy or errors (Yule, 2020; Zahro, 2019). Enormous errors affecting listeners' understanding lead to intelligibility compared to other factors (Levis, 2018). Between two kinds of pronunciation features proposed by Levis (2018), the word-based pronunciation feature is applicable to examine since intelligibility is a word-based measurement. One of the features that has a significant impact on intelligibility is segmental. Crowther (2020) highlights that segmental sound is one of the significant measures of speech production. Errors in both types of segmental; consonants and vowels are the primary root of the listeners' trouble to write out the speech words by words (Levis, 2018). Two essential concepts are used to examine segments: phonological operation and phonetic transcription. Phonological operation is a process of adjusting and manipulating specific segments through deleting, inserting, or substituting some or whole segments (Davenport \& Hannahs, 2020). Furthermore, phonetics transcription is based on the International Phonetic Alphabet revised to 2020 (Zimman, 2020) as the phonetic symbols to represent the produced sounds.

\subsection{Listeners' Awareness}

Awareness happens when a person is conscious and notices some difference in an experience (Drager \& Kirtley, 2016: 1). Moreover, McGowan (2016: 29) terms listeners' awareness as the ability made by the listeners in noticing various patterns of linguistic contained in a speech. In sociolinguistics variables, such as accent, Drager and Kirtley (2016: 11 ) is believed that listeners' awareness affect speech perception. Furthermore, studies on speakers' awareness show that self-assessment as a tool to speakers' awareness has influenced comprehensibility (Strachan et al., 2019). However, studies on listeners' awareness of speech related to the intelligibility that brings about pronunciation errors are hardly found.

Previous studies about pronunciation awareness have been written by Menzer (2017) and Strachan et al., (2019) merely related to speakers' awareness of their comprehensibility. Menzer (2017) investigates German accented speakers' awareness of native English speakers' actual speaking to assist the German speaking comprehensibility and intelligibility. Meanwhile, Strachan et al., (2019) examine Mandarn speakers who perform English oral task rated by native-speaking listeners. Both studies show that speakers' awareness through their self-assessment and phonological awareness have affected their comprehensibility (Menzer, 2017; Strachan et al., 2019). However, both results of the studies have been unable to demonstrate the issue of listeners' awareness. The findings of those previous studies are therefore limited to speakers' awareness. They have not previously described the listeners awareness of speakers' speech. Hence, there is an important issue about the listeners' awareness of the speakers' oral production. The present study aims to investigate the gap. 
Unintelligible Speech: Listeners' Awareness to Indonesian-Accented Speech with Pronunciation Errors, Syifa' Khuriyatuz Zahro

\section{Research Method}

A qualitative descriptive method is applied to describe the pronunciation errors in the segmental level and listeners' awareness of the errors to reach the research objective. Four listeners of native and non-native speakers of English assess six speech samples spoken in three Indonesian accents: Banjarese, Madurese, Sundanese accented English obtained from purposive sampling. The participants to provide insightful data are selected based on particular criteria: Indonesian people who have minimally five years' experience in English education, own L1, and speak English with an L1 accent

The data collected are the listeners' orthography transcripts of six speech samples provided by the Indonesian-accented speakers. In addition, they have recorded the reading test of SPIN material. The dictation task is the primary technique to collect the data where the listeners transcribe the speech samples in standard orthography transcription. In addition, the orthography transcript data were further converted to phonetic transcription based on the International Phonetic Alphabet - revised to 2020 (Zimman, 2020). Other data gained from the result of error analysis are further clarified and checked through the native speaker of English interview by using an interview guide adapted from Crowther (2018) and Paakki (2013).

The analysis of the phonemic transcript is conducted through error analysis following the phonological operation by Davenport \& Hannahs (2020) by comparing the phonemic transcript of the original phonemic transcript of the speech material to find the errors. Furthermore, to have a reliable finding and check the listeners' awareness of the errors, a member check is conducted through interviews with the native speakers who provide feedback about the research's findings to avoid missing insight. After all, the result is additionally confirmed using triangulation.

\section{Results and Discussion}

The error analysis of segmental features between vowels and consonants of Indonesianaccented speech generate that consonants give more influence to cause unintelligible speech for the listeners, as in figure 1. The percentage is in accordance with the result of member check from the listeners that speakers' consonant mispronunciation is more complicated than vowels. The listeners believe that it might be the interference of speakers' native language sounds.

Figure 1.The Segmental Errors Percentage

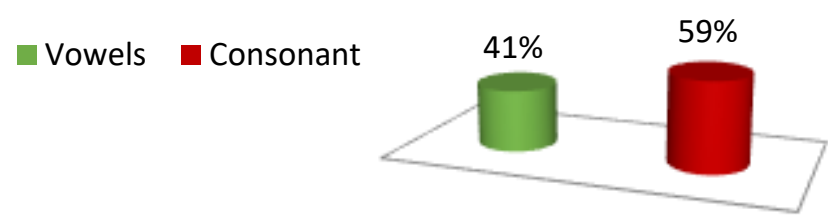

This result reinforces the study by Jenkins (2002) and Beinhoff (2014: 47), who believe that consonant variation is more problematic that can lead to unintelligibility. Also, the finding repudiate Yule's (2020) claims that vowels dominantly cause errors.

Additionally, the overview of the errors in consonants identification to cause unintelligible speech can be seen below: 
Figure 2. The Errors in Consonants Identification Percentage

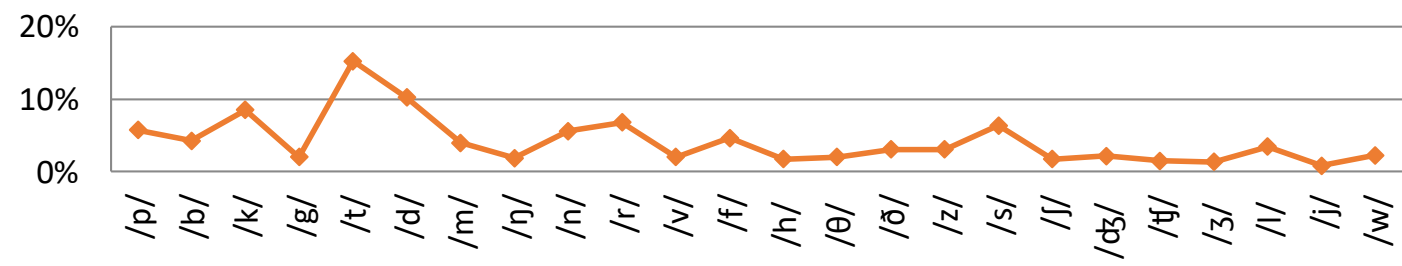

The figure shows that 24 errors in consonants, /t/, /d/, and / k/ are the highest error identification percentage where / $\mathrm{t} /$ phoneme error is $15 \%, / \mathrm{d} /$ phoneme is $10 \%$, and / $/ \mathrm{k} /$ phoneme is $8 \%$. The listeners agree that $/ t /$ phoneme pronunciation by some speakers is weird for them.

On the other hand, English vowels errors identification have also been distinguished by the listeners. A few unintelligible words originate from vowels because the English and Indonesian vowels system are different. The analysis of errors identification in vowels can be depicted below:

Figure 3. The Errors in Vowels Identification Percentage

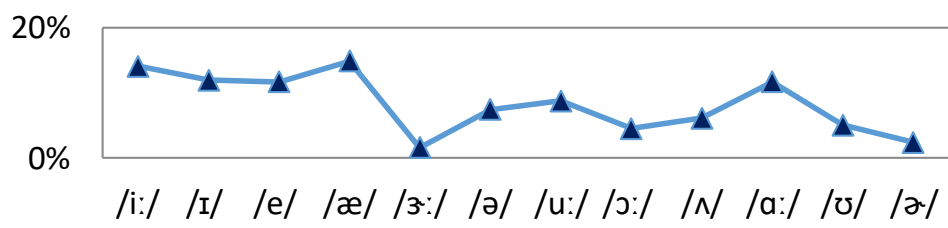

The above figure clearly shows us that significant amounts of errors on vowel are /æ/ phoneme in $15 \%$ and /i:/ phoneme in $14 \%$. Meanwhile, the smallest part of vowel errors is $/ 3:$ / phoneme in $2 \%$. It can be affected by some English vowels that do not exist in the Indonesian phonological system. Therefore, it hinders Indonesian speakers from producing some errors in the pronunciation of some English vowels.

In addition, the source of both consonant and vowel errors is further analyzed and yields six main features that affect listeners' awareness of speakers' pronunciation errors. They are; 1) aspiration, 2) spelling system, 3) blended phonemes, 4) absent phonemes, 5) different articulation, and 6) homophone.

\subsection{Aspiration}

The finding that aspiration as the first source of error identification is consistent with that of Gani (2002) and Andi-Pallawa (2013), who believe that /p/, /t/, and /k/ phonemes caused pronunciation errors. The errors of $/ \mathrm{p} /, / \mathrm{t} /$, and $/ \mathrm{k} /$ phonemes by Indonesian speakers are the result of the absent of aspiration in Indonesian $/ \mathrm{p} /, \mathrm{t} /$ and $/ \mathrm{k} /$ phonemes. Another aspiration error is originated from $/ \mathrm{t} /$ where it is aspirated as $/ \mathrm{p} /, / \mathrm{t} /$, and $/ \mathrm{k} /$. In Indonesian phonemes, especially in Sundanese and Banjarese phonemes, $/ \mathrm{t} /$ phoneme is the same as /ĉ/. On the other hand, Madurese has neither / $t /$ or / $\hat{c} /$ (Andi-Pallawa \& Alam, 2013).

Indonesian speakers mostly omit / $t$ / phoneme, but some substitute it, while most of them substitute $/ \mathrm{k} /$ and $/ \mathrm{p} /$ phonemes more instead of omitting them. Their amount of errors was $15 \%$ for $/ \mathrm{t} /$ phonemes, $8 \%$ for $/ \mathrm{k} /$ phoneme, and $6 \%$ for $/ \mathrm{p} /$ phoneme. This finding was supported in the interview result by the listeners who confirmed that Indonesian 
Unintelligible Speech: Listeners' Awareness to Indonesian-Accented Speech with Pronunciation Errors, Syifa' Khuriyatuz Zahro

speakers pronounced consonants in a voiceless way so that the listeners were distracted in comparison to their English pronunciation. Another aspiration error originated from $/ \mathrm{t} / \mathrm{s} / \mathrm{t} /$ phoneme is only found in $1 \%$ of error.

\subsection{Spelling System}

Except aspiration, some of English spelling systems have been considered as the source of errors, they are are phoneme of final -ed and final $-\mathrm{s}$ spelling, spelling of $/ \mathrm{s} / \mathrm{,} / \mathrm{z} /, \mathrm{w} /$,

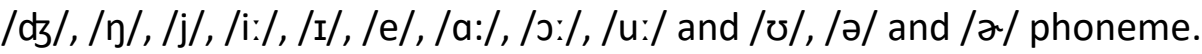

Three different pronunciations of final-ed spelling in English lead to confusion for Indonesian speakers and cause pronunciation errors. However, the listeners note that they mostly do not hear the final -ed pronounced by Indonesian speakers, who mostly ignore it by omission ( $80 \%)$ and substitution (20\%).

The final $-s$ spelling is pronounced as three ways; [s] preceded by all voiceless consonants except /s/ and / $\mathrm{t} /$, [z] preceded by voiced consonant except /z/ and /dz/, and [Iz] preceded by $/ \mathrm{s} /, / \mathrm{z} /, / \mathrm{t} /$ and $/ \mathrm{d} 3$ (Cruttenden, 2014). Similar to final -ed spelling, final $-\mathrm{s}$ is mostly omitted (72\%), substituted (18\%) or inserted (9\%). English /s/ phoneme is spelled in many ways c-, s-, sc-, -c-, -s-, -ss-, -ce, -s, -se and -ss (Cruttenden, 2014). Indonesian spelling of $/ \mathrm{s} /$ phoneme is only $-\mathrm{s}-$. It is found that errors in $/ \mathrm{s} /$ and $/ \mathrm{z} /$ are a result of the various English spelling system for the phoneme $/ \mathrm{s} /$ and $/ \mathrm{z} /$. Indonesian speakers do a substitution (66\%), omission (17\%) or insertion (17\%).

English /w/ phoneme is spelled by $-\mathrm{w}-, \mathrm{u}-,-0$, and wh- clusters. While Indonesian /w/ phoneme is also represented by-u-. Only $2 \%$ of error emerges in the spelling of $/ \mathrm{w} /$ phoneme as in "one" and "won" pronounced the same as [w/n].

In English, / $\mathrm{d}_{3} /$ phoneme is equivalent to / $/$ / or $/ \mathrm{j} /$ Indonesian phonemes in most Indonesian local languages. English / $\mathrm{d}_{3} /$ phoneme may be spelled by $-\mathrm{j},-\mathrm{g}$, and $-\mathrm{dg}$-. The error of $/ \mathrm{d} /$ / phoneme was $2 \%$ of substitution.

Both Indonesian and English $/ \mathrm{h} /$ phonemes that are spelled as -ng-. English $/ \mathrm{h} /$ never appear initially, while Indonesian / $\mathrm{y} /$ appears in all positions (Davenport \& Hannahs, 2020). The English medial $/ \mathrm{h} /$ is spelled in -ng- or -ngg-, middle -ng with one morpheme in a word uttered as [ng] with additional [g], while middle -ng with two morphemes in a word is articulated simply as [n] (Roach, 2009). Except in comparative and superlative with final -er and -est considered one morpheme (Roach, 2009). In contrast, the spelling of Indonesian / $\mathrm{ng} /$ phoneme is -ngg-. The errors on $/ \mathrm{h} /$ phoneme appears by substitution in $2 \%$.

English /j/ phoneme and Indonesian /y/ phonemes are the same (Davenport \& Hannahs, 2020; Muslich, 2008). In phonetics, Roach (2009) highlights that this phoneme is similar to vowel /i:/, but it is a consonant phonologically. The spelling of English /j/ phoneme can be written as $y$ - or unwritten like when it followed by $/ \mathrm{u}: /, / \mho /$, and -ə. The errors found for $/ \mathrm{j} /$ phoneme is $1 \%$ insertion.

English /i:/ phoneme holds one variant /I/, quite shorter than /i:/ (Davenport \& Hannahs, 2020). Both /i:/ and /I/ are spelled in many ways. Conversely, Indonesian /i/ phoneme has two allophones; [i] and [I] (Muslich, 2008). English /i:/ phoneme in initial frequently spelled in e-, in medial can be -i-, -ea-, -ei-, -ie-, and in final it can be -e, and -ee. (Cruttenden, 2014). Additionally, the spelling of English /I/ phoneme is also like initial e-, medial -i-, medial - $y-$, medial -u-, medial -o-, medial -a-, medial - $u$, and medial -ia(Cruttenden, 2014). The errors found from /i:/ phoneme are substitution in 14\%, while /I/ phoneme is also substituted in $12 \%$. In /i:/ phoneme errors, the listener, a native speaker, notices double vowel like -ee- that it is pronounced by simply pronouncing the first. 
Both $/ \varepsilon /$ and /e/ phonemes are equal in General American English. In contrast, two allophones of /e/ phoneme in Bahasa Indonesia are [e] and [ $\varepsilon]$. English /e/ phoneme is placed in initial and medial, whereas Indonesian also in final (Davenport \& Hannahs, 2020). In English, /e/ phoneme is spelled in initial e-, initial -a, medial -ea-, medial -ie-, medial -ai-, medial -eo- (Cruttenden, 2014). The error found is a substitution of /e/ phoneme in $12 \%$. One of the substitutions is from /e/ phoneme to /I/ phoneme that believed by the listener because of the speakers' incorrect pronunciation in the spelling -ea.

General American /a:/ phoneme is represented in many spelling; initial a-, initial ou-, medial -a-, medial -o-, medial -ea-, medial -ou-, medial -ow-, final -aw (Cruttenden, 2014). On the other hand, General American has /a:/ the same as Indonesian phoneme /a/ that is spelled -a-.

In English, /u:/ phoneme has one variant, / / phoneme (Davenport \& Hannahs, 2020). English / $u /$ phoneme occurs in medial and final. Both / $u: /$ and $/ v /$ phonemes have different spelling system. English /u:/ phoneme is spelled in medial -o-, medial -u-, medial -ew-, medial -oo-, medial -ou-, medial -ui-, final -o, and final -ue. Besides, / $/$ / phoneme is spelled in medial -o-, medial -u-, medial -oo-, medial -ou- (Cruttenden, 2014). The errors analysis reveales that errors of both phonemes are in the forms of substitution; / $u$ :/ is substituted in $9 \%$, and $/ \mho /$ phoneme is $5 \%$ substituted.

English and Indonesian /ə/ phoneme are generally known as schwa in initial and medial, but English /ə/ phoneme may also appear in the final position (Davenport \& Hannahs, 2020; Muslich, 2008). In English, /ə/ phoneme may be spelled in all vowels, -a-, -i-, -u-, -e-, and -o-, but in Bahasa Indonesia, it is spelled only as -e- (Roach, 2009). To this effect, Indonesian speakers may find it hard to differentiate which vowels must be pronounced by $/ \partial /$ phoneme. Furthermore, General American English has / $/$ phoneme as a final schwa added by pronounced $/ r /$. The phoneme $/ \partial /$ is spelled by $-r$ preceded by some vowels like -ar, -ure, er, and -or (Roach, 2009). The errors analysis shows that /ə/ phoneme mainly is substituted by other vowels in $7 \%$, and the final $/ r /$ in $/ \partial /$ phoneme is omitted in $2 \%$.

In English, / $:$ / phoneme is similar to Indonesian /o/ phoneme. They may appear either in initial, medial, or final words. Indonesian /o/ phoneme is an allophone of [O] phoneme (Muslich, 2008). English /د:/ phoneme can be represented for most vowel letters as initial o-, medial -o-, medial -a-, medial -oa-, medial -ou-, medial -oo-, final -our, final -ore (Cruttenden, 2014). Those several spellings of / $\mathrm{J}: /$ phoneme possibly complicate Banjarese speakers who have no / $\mathrm{J}$ / phoneme in Banjarese phonological system. It is proved from the error analysis /د:/ phoneme errors are substituted in 5\%.

\subsection{Blended Phonemes}

Blended phonemes in the form of consonant clusters for blended consonants and diphthongs for blended vowels are the other sources of errors. Among 24 errors in consonants clusters, $67 \%$ are from a word with two consonants, $29 \%$ are from a word with three consonants, and $4 \%$ are from a word with four consonants.

A consonant cluster can consist of two, three, or more consonants in one word in English. Nevertheless, Bahasa Indonesia has no consonant cluster. Therefore, it obstructs Indonesian speakers' pronunciation and makes the listeners perceive some errors and is considered unintelligible speech. Indonesian speakers' errors in English consonant clusters were because consonant clusters in Bahasa Indonesia originated from European loan words that influenced Indonesian speakers' articulation. Gani (2002) defines this trend as a 
Unintelligible Speech: Listeners' Awareness to Indonesian-Accented Speech with Pronunciation Errors, Syifa' Khuriyatuz Zahro

simplification because consonant clusters do not exist in the Indonesian phonological system.

Another source of unintelligible speech of Indonesian speakers is a diphthong, two vowels combination in a syllable. Four out of five American English diphthongs have proved to affect Indonesian speech perceived unintelligible by the listeners; they are [er], [ar], [ov], and [av]. The percentages of diphthong errors are [eI] in 36\%, [aI] in 32\%, [ov] (also absent in Indonesian diphthong) in 23\%, and [av] in $9 \%$. The error analysis yields that most of the English diphthongs are substituted by Indonesian speakers and lead to an unintelligible speech. The finding of diphthong as a source of pronunciation error is consistent with Gani (2002), finding mispronunciation of /av/, /aI/, /JI/ and /av/ leading to an unintelligible speech.

\subsection{Absent phonemes}

The absence of particular English phonemes in Indonesian phonemes is the source of errors and unintelligible speech. To this effect, Indonesian speakers tend to do substitution for the absent phonemes. It is mainly in the form of English fricative phonemes $/ \mathrm{v} /, / \theta /, / \delta /$, $/ \mathrm{S} /$, and $/ 3 /$ as well as vowel phonemes with many spelling $/ æ /, / \Lambda /$, and $/ 3: /$.

English /v/ phonemes are frequently substituted by /f/ as Madurese speakers who articulate [f] sound for / $/$ / phoneme (Wahyuningrum, 2006: 75). On the other hand, no / $/ \mathrm{d}$ phoneme is found in Sundanese and Banjarese phonemes. Thus, the speakers tend to substitute $/ \mathrm{v} /$ phoneme in $2 \%$ of errors.

English $/ \theta /$ and $/ \delta /$ phonemes are spelled in "th", a consonant cluster absent in Indonesian phonemes. These phonemes are substituted or omitted in $2 \%$ for $/ \theta /$ phonemes and $3 \%$ for $/ \delta /$ phoneme. The speakers tend to fully omit "th" $/ \theta /$. They also substitute them by adjacent phonemes like /t/, /d/, / $/$, and /f/ phonemes. Additionally, /J/ phoneme is substituted by $/ \mathrm{t} /$ as well as substituted by $/ \mathrm{d} /$.

English phonemes $/ \mathrm{J} /$ and $/ 3 /$ cannot be found in the Indonesian phonemes, yet it is the same as the Indonesian / $\hat{s} /$ phoneme. Indeed, both phonemes are slightly different. English $/ \mathrm{J} /$ is rounded while Indonesian $/ \hat{\mathrm{s}} /$ is unrounded. It is found only $2 \%$ error in the pronunciation of $/ \mathrm{J} / .60 \%$ of them are omitted, and $40 \%$ of them are substituted. On the other hand, $/ 3 /$ phoneme has only $1 \%$ error in a substitution.

English phoneme /æ/ gains the most frequent vowel error in $15 \%$. Indonesian speakers substitute it by similar phoneme like /e/ and / $\varepsilon /$ phoneme to /æ/, schwa /ə/ or diphthong /eI/. Thus, the substitution for /æ/ phoneme, a non-existed phoneme in Indonesian phoneme, is /e/, /ə/, or /ei/ phonemes.

English phoneme $/ \Lambda$ / does not exist in Indonesian phoneme so that it substituted by /a:/, /æ/, /u:/ phonemes or /ov/ and /aI/ diphthong. This phoneme emerges as a critical problem that is perceived differently from the original because it has many spelling systems as -o-, u-, -ou-, -oo-, and -oe-(Andi-Pallawa \& Alam, 2013). American listeners believe that such different spelling of most vowels cause vowel confusion among English native speakers, where Indonesian speakers pronounce them differently from their standard pronunciation.

English /3:/ phoneme with $2 \%$ or errors also has several different spelling as -ear-, -er , ear-, -ur-, -ir-, -or- and -ur-(Andi-Pallawa \& Alam, 2013). It is apparent that numerous spelling systems have made listeners perceive them differently.

The absent phonemes of English in Indonesian phonological systems as the fourth source of error identification are frequently naturalized on the basis of articulation place that is in line with Gani (2002). Such naturalization originates from the speakers' L1 peculiar 
sounds. Those consonants are absent in Indonesian phonological systems, but the vowels mentioned above also do not exist in the Indonesian phonological system, particularly Banjarese, Madurese and Sundanese languages. Therefore, most speakers do the naturalization of those absent vowels to the existing vowels in their language.

\subsection{Different Articulation}

Manner and place of articulation of some English phonemes have significant differences in comparison to Indonesian. The errors analysis yields that source of errors from phonemes with different articulation is final phoneme $/ d /$, phoneme $/ \mathrm{r} /, / \mathrm{b} /, / \mathrm{g} /, / \mathrm{l} /, / \mathrm{h} /$, and pronunciation of particular name.

In Indonesian word, final [d] phoneme is pronounced as [t]. English words are ended with $-d$ mostly substituted by [t]. The substitution of final / $d /$ phoneme appears to another plosive alveolar phoneme /t/ or similar plosive / $/$ / and alveolar /s/. Furthermore, the omission and insertion of final / $d /$ happens when needed to contextualize the sentence, as it is unheard.

English and Indonesian's phonemes $/ r$ / are entirely dissimilar. English $/ r$ / is approximant postalveolar while the Indonesian $/ r$ / is trill alveo-dental. The phoneme $/ r$ / errors commonly happen by omitting $/ r$ / phoneme. Oversimplification of $/ r /$ phoneme lead to the omission of this phoneme. In addition, insertion and substitution of $/ r /$ phoneme to its adjacent approximant like /w/ and /// emerge caused by speakers' careful pronunciation of / $/ \mathrm{l}$ phoneme expected to be a native-like, yet bring about unvoiced $/ r /$. Therefore, the $/ r /$ sound might not be heard, so they ignore it.

Final phoneme $/ \mathrm{b} /$ and $/ \mathrm{g} /$ in Indonesian language is slightly different from English. The substitution of $/ \mathrm{d} /, / \mathrm{f} /, / \mathrm{p} /, / \mathrm{t} /$ for $/ \mathrm{b} /$ and the substitution of $/ \mathrm{k} /, / \mathrm{d} /$ for $/ \mathrm{g} /$ are major source of errors in final $/ \mathrm{b} /$ and $/ \mathrm{g} /$. The errors analysis yields that omission and insertion are hardly found. Besides, it is observed the errors of phoneme $/ \mathrm{h} /$ are in the form of substitution of $/ \mathrm{w} /, / \mathrm{r} /$, and $/ / /$ phoneme.

The presence of three allophones of English /// phoneme; clear ///, dark /// and devoiced /I/ lead to a problem for Indonesian speakers. The errors analysis yields that silent $/ \mathrm{I} / \mathrm{is}$ correctly transcribed, while words with dark /I/ are dominantly substituted by $/ \mathrm{r} / \mathrm{,} / \mathrm{d} / \mathrm{l}, \mathrm{t} / \mathrm{s}$ and $/ \mathrm{n} /$. The substitution of dark $/ \mathrm{l} / \mathrm{is}$ apparent to adjacent approximant as $/ \mathrm{r} / \mathrm{or} / \mathrm{w} /$, some voiced consonants as $/ \mathrm{d} /, / \mathrm{n} /, / \mathrm{m} /$, another alveolar as $/ \mathrm{t} /$ phoneme or a velar as $/ \mathrm{k} /$ phoneme. In addition, the substitution is tailed by some omission and an insertion is observed only one error.

Indonesian has phoneme $/ \mathrm{h} /$ in all positions and the final $/ \mathrm{h} /$ is strong. English initial $/ \mathrm{h} /$ can be a clear $/ \mathrm{h} /$ and silent $/ \mathrm{h} /$. Meanwhile, these two articulation ways are also applied in Indonesian medial $/ \mathrm{h} /$ such as clear $/ \mathrm{h} /$ in and silent $/ \mathrm{h} /$. The problem of phoneme $/ \mathrm{h} /$ is occurred when clear /h/ is spelled by " $w$ " as whole /hovl/ (Roach, 2009). Thus, the errors of $/ \mathrm{h} /$ are a substitution of the $\mathrm{w} /, / \mathrm{r} /$ and $/ \mathrm{I} /$ phoneme.

Furthermore, the interview result yields that the pronunciation manner of English and Indonesia of particular names bring about unintelligible speech. Indonesian has different ways to pronounce names compared to English, so that it is naturalized to Indonesian tongue and phones. For example, a name like "David" is pronounced in Indonesia as [davit] while in English, it articulated as ['deIvid]. In addition, it appears to be monophthongization of the diphthong [er] in English into a pure vowel [a] in Indonesia. Those two name pronunciation styles lead to confusion among the listeners and cause some errors in the listeners' transcript. 
Unintelligible Speech: Listeners' Awareness to Indonesian-Accented Speech with Pronunciation Errors, Syifa' Khuriyatuz Zahro

All of the abovementioned phonemes are also in line with Andi-Pallawa and Alam (2013), where some or few differences are in the way they are articulated in Indonesian pronunciation. Additionally, the finding of the careful pronunciation of $/ r /$ phoneme yields to devoiced / $r$ / contradicted to Gani (2002) that suggests over trilling is the source of errors in Surabayanese speakers.

\subsection{Homophone}

The last finding that is the most remarkable is homophone. It is concerned with two words that have precisely the same phonemes phonemically and phonetically. However, both words are spelled differently. For example, it is found in the word won and one pronounced as /w^n/, rode and road are pronounced the same as/roud/ as well as knob and nob pronounced as /na:b/. Therefore, those homophone words are observed to cause unintelligibility. It is in line with the interview results that homophone makes it difficult to decide which words are more likely to suit the speech sample sentences. Hence, a homophone of some words found in the sentence like won and one and rode and road make the speech unintelligible and contribute to the listeners' transcript errors.

\section{Conclusion}

The study aims to find out segmental features and the sources of errors that cause unintelligible speech of Indonesian-accented speech and describe the listeners' awareness of the errors. The conclusion drawn from the result is that the pronunciation errors at the segmental level are dominated by errors in consonants confirmed by Beinhoff's (2014) and Jenkins' (2002) studies that constantly discover consonants as more problematic segments than vowels. On the other hand, this finding is contradicted with Yule's (2020) study believing that vowels are more likely to dominate the errors.

Furthermore, six sources of pronunciation errors are made by the speakers that the listeners also realize. The sources of errors are; 1) aspiration, 2) spelling system, 3) blended phonemes, 4) absent phonemes, 5) different articulation, and 6) homophone.

This study is to find out pronunciation errors made by Indonesian-accented speakers. Thus, it is strongly suggested that the Indonesian English teachers, particularly in Banjarese, Madurese, and Sundanese, give more attention to the six sources of errors in teaching pronunciation, both consonant and vowels, and they are to be accurately drilled and familiarized with the students to speak intelligibly. In addition, to the upcoming research, since the current study is concerned only with segmental features, the need to focus on the broader scope of pronunciation features like supra-segmental or prosodic features must be examined as what have been suggested by the listeners of the native speakers of English.

\section{References}

Andi-Pallawa, B., \& Alam, A. F. A. (2013). A Comparative Analysis between English and Indonesian Phonological Systems. International Journal of English Language Education, 1(3), 103-129.

Behrman, A., Ferguson, S. H., \& Flom, P. (2020). The Effects of Clear Speech on American English Listener Perception of Spanish-Accented and Native English Speech. Perspectives of the ASHA Special Interest Groups, 5(6), 1698-1709.

Beinhoff, B. (2014). Perceiving Intelligibility and Accentedness in Non-Native Speech: A Look at Proficiency Levels. Concordia Working Papers in Applied Linguistics, 5, 58-72. https://doi.org/10.1080/026404101750070193 
Crowther, D. (2020). Measuring Phonology. New York: The Routledge Handbook of Second Language Acquisition and Language: Testing.

Crowther, D. J. (2018). Linguistic Measures of Second Language Speech: Moving from Monologic to Interactive Speech. Michigan: Michigan State University.

Cruttenden, A. (2014). Gimson's Pronunciation of English. Routledge.

Davenport, M., \& Hannahs, S. J. (2020). Introducing Phonetics and Phonology (Fourth Ed.). New York:Routledge.

Drager, K., \& Kirtley, M. J. (2016). Awareness, Salience, and Stereotypes in Exemplar-Based Models of speech Production and Perception. Awareness and Control in Sociolinguistic Research, 1-24.

Gani, Y. D. (2002). A phonological Study on the Influence of Surabayanese Accent in English Pronunciation among Some Indonesian Members of the British Council/ITS English Study Centre.Surabaya: Petra Christian University.

Gao, Z., \& Weinberger, S. (2018). Which Phonetic Features Should Pronunciation Instructions Focus on? An Evaluation on the Accentedness of Segmental/Syllable Errors in L2 Speech. Research in Language, 16(2), 135-154.

Jenkins, J. (2002). A Sociolinguistically Based, Empirically Researched Pronunciation Syllabus for English as an International Language. Applied Linguistics, 23(1), 83-103.

Levis, J. M. (2018). Intelligibility, Oral Communication, and the Teaching of Pronunciation. Cambridge : Cambridge University Press.

Lindemann, S. (2017). Variation or 'Error'? Perception of Pronunciation Variation and Implications for Assessment. Second Language Pronunciation Assessment, 193.

Liu, L., \& Jaeger, T. F. (2019). Talker-specific Pronunciation or Speech Error? Discounting (or not) a Typical Pronunciations during Speech Perception. Journal of Experimental Psychology: Human Perception and Performance, 45(12), 1562.

McGowan, K. B. (2016). Sounding Chinese and listening Chinese: Awareness and Knowledge in the Laboratory. Awareness and Control in Sociolinguistic Research, 25-61.

Menzer, K. (2017). Phonological Awareness and Foreign Accent: A Handbook for German EFL Teachers. $\quad$ https://www.semanticscholar.org/paper/Phonological-Awareness-andForeign-Accent\%3A-A-for-Menzer/bbe50b689f042523a5a44e9a0d9bc4ce9f025d5f.

Munro, M. J., \& Derwing, T. M. (2020). Foreign Accent, Comprehensibility And Intelligibility, Redux. Journal of Second Language Pronunciation, 6(3), 283-309.

Muslich, M. (2008). Fonologi Bahasa Indonesia: Tinjauan Deskriptif Sistem Bunyi Bahasa INDONESIA. Jakarta: Bumi Aksara.

Paakki, H. (2013). Difficulties in Speaking English and Perceptions of Accents: A Comparative Study of FINNISH and Japanese Adult Learners of English. Itä-Suomen yliopisto. https://erepo.uef.fi/bitstream/handle/123456789/13022/urn_nbn_fi_uef20131057.pdf.

Rahimi, M., \& Ruzrokh, S. (2016). The Impact of Teaching Lingua Franca Core on English as a foreign Language Learners' Intelligibility and Attitudes towards English Pronunciation. Asian Englishes, 18(2), 141-156.

Roach, P. (2009). English Phonetics and Phonology Paperback with Audio CDs (2): A Practical Course. Cambridge: Cambridge university press.

Sereno, J., Lammers, L., \& Jongman, A. (2016). The Relative Contribution of Segments and Intonation to the Perception of Foreign-Accented Speech. Applied Psycholinguistics, 37(2), 303.

Smith, L. E., \& Nelson, C. L. (2019). World Englishes and Issues of Intelligibility. The Handbook 
Unintelligible Speech: Listeners' Awareness to Indonesian-Accented Speech with Pronunciation Errors, Syifa' Khuriyatuz Zahro

of World Englishes, 430-446. http://myjms.mohe.gov.my/index.php/ajress/article/view/10699.

Strachan, L., Kennedy, S., \& Trofimovich, P. (2019). Second Language Speakers' Awareness of Their own Comprehensibility: Examining Task Repetition and Self-Assessment. Journal of Second Language Pronunciation, 5(3), 347-373.

Suntornsawet, J. (2019). Problematic Phonological Features of Foreign Accented English Pronunciation as Threats to International Intelligibility: Thai EIL Pronunciation Core. Journal of English as an International Language, 14(2), 72-93.

Wahyuningrum, R. (2006). A Phonological Analysis of English Speech Sounds Produced by Madurese EFL. Unpublished Thesis. Surabaya: Unesa.

Yule, G. (2020). The study of Language. Cambridge: Cambridge university press.

Zahro, S. K. (2019). Native and Non-Native Listeners Perceptual Judgement of English Accentedness, Intelligibility, and Acceptability of Indonesian Speakers. Lingua Cultura, 13(1), 39-44. https://doi.org/10.21512/LC.V13I1.5362

Zimman, L. (2020). International Phonetic Alphabet. The International Encyclopedia of Linguistic Anthropology, 1-6. 